\title{
A conceptual model for vision rehabilitation
}

\author{
Pamela S. Roberts, PhD, OTR/L, SCFES, FAOTA, CPHQ, FNAP ( $^{*}$ John-Ross Rizzo, MD; $^{2}$ Kimberly Hreha, \\ MS, OTR/L; ${ }^{3}$ Jeffrey Wertheimer, PhD, ABPP-CN; ${ }^{1}$ Jennifer Kaldenberg, MSA, OTR/L, SCLV, FAOTA; ${ }^{4}$ \\ Dawn Hironaka, BS, OTR/L; ${ }^{1}$ Richard Riggs, MD; ${ }^{1}$ August Colenbrander, MD $^{\mathbf{5}}$ \\ ${ }^{1}$ Department of Physical Medicine and Rehabilitation, Cedars-Sinai Health System, Los Angeles, CA; ${ }^{2}$ Department of \\ Rehabilitation Medicine, New York University Langone Medical Center, New York, NY; ${ }^{3}$ Kessler Institute for Rehabilitation \\ and Kessler Foundation, West Orange, NJ, and Teachers College, Columbia University, New York, NY; ${ }^{4}$ College of Health \\ and Rehabilitation Sciences, Boston University, Boston, MA; ${ }^{5}$ Smith-Kettlewell Eye Research Institute, San Francisco, CA
}

\begin{abstract}
Vision impairments are highly prevalent after acquired brain injury (ABI). Conceptual models that focus on constructing intellectual frameworks greatly facilitate comprehension and implementation of practice guidelines in an interprofessional setting. The purpose of this article is to provide a review of the vision literature in ABI, describe a conceptual model for vision rehabilitation, explain its potential clinical inferences, and discuss its translation into rehabilitation across multiple practice settings and disciplines.
\end{abstract}

Key words: acquired brain injury, conceptual model, functional vision, interprofessional, rehabilitation, stroke, vision, vision assessment, vision specialists, visual function.

\section{INTRODUCTION}

Vision is one of our primary senses and is used continuously to gather information during functional activity. The visual system is a sensitive and highly complex neural network that provides the sensory input (afferent vision) required to interact with our dynamic environment [1] in addition to the eye movements (efferent vision) that improve the visual percepts needed for spatial planning and object identification. During any medical assessment, vision is a critical component to consider, regardless of clinical setting, demographics, or discipline. Globally, the World Health Organization (WHO) has estimated that visual impairment of all etiologies affects nearly 285 million people [2].
Individuals with vision impairment often experience significantly increased morbidity, which is amplified when related sensory and functional deficits are not comprehensively managed. Those with visual impairment have twice the risk for falling, over four times the risk for sustaining a hip fracture [3-5], and three times the risk for clinical depression [6-7]. Persons with impaired vision may also have increased social isolation [8]; greater difficulty reading information, such as their medication bottles [9]; earlier nursing home placement [10] and community services utilization [11]; and increased mortality [11-12].

In general, vision deficits are typically associated with problems with visual acuity and visual fields. Unfortunately, this narrow conceptualization does not incorporate the visual perceptual or oculomotor deficits that are

\footnotetext{
Abbreviations: $\mathrm{ABI}=$ acquired brain injury; $\mathrm{ACRM}=$ American Congress of Rehabilitation Medicine; ADL = activities of daily living; IADL = instrumental activities of daily living; ICF = International Classification of Functioning, Disability, and Health; ISIG = Interdisciplinary Special Interest Group; TBI = traumatic brain injury; WHO = World Health Organization.

*Address all correspondence to Pamela S. Roberts, PhD, OTR/L, SCFES, FAOTA, CPHQ, FNAP; Department of Physical Medicine and Rehabilitation, Cedars-Sinai Health System, 65600 Wilshire Blvd, Suite 1511, Los Angeles, CA 90048; 310-423-6660. Email: pamela.roberts@cshs.org http://dx.doi.org/10.1682/JRRD.2015.06.0113
} 
paramount to cognitive and motor abilities, deficits that affect the majority of individuals with acquired brain injury (ABI) [13]. In fact, oculomotor dysfunction has been estimated to be as high as 90 percent in individuals with traumatic brain injury (TBI), followed by accommodative and convergence deficits [14-15]. Strabismus, cranial nerve palsies, visual field loss, and oculomotor deficits also occur frequently in stroke [14-15]. A review of these common visual impairments is included in the Table [1,8,16-19,22].

It is estimated that approximately 25 percent of the neocortex in humans is devoted to vision [13]. Therefore, it follows that the prevalence and incidence of visual impairments in $\mathrm{ABI}$ is high, secondary to this pervasive and highly interconnected neural network. These frequent visual deficits magnify limitations in independence in a myriad of ways, because the vast majority of functional activities are visually dominant. It is well known that vision problems in stroke and TBI are associated with limitations in activities of daily living and instrumental activities of daily living (ADL/IADL) [3-5,8,1012,20-21]. Moreover, functional implications of the impaired visual system may limit recovery and progress during standard rehabilitation and decrease overall quality of life [22].

Despite these potentially profound functional effects, there is not a systematic approach to comprehensive visual assessment and management. This is in contrast to impairments in the language/speech, cognitive, and motor domains, all of which have developed rehabilitative [4] conceptual models that are universally accepted, mature, and implemented as part of neurorehabilitation. We believe vision rehabilitation is immature by comparison [20-21], secondary to the multifaceted nature of vision and the complexity of visual dysfunction following ABI; we further believe that a new focus on an optimized conceptual model that guides clinicians through the referral stream, in addition to screening tools and care models, will lead to a paradigm shift.

Organizations have created guidelines, written articles, and initiated dialog; however, the recommendations are only for select populations, specific professionals, or one aspect of vision care or are not dedicated to rehabilitation [23-28]. These include the American Occupational Therapy Association [29], the Neuro-Optometric Rehabilitation Association [30], and the American Optometric Association [31]. Individual professionals have also contributed significantly to the creation of frameworks or concepts in vision rehabilitation. Warren developed an organizational tool with a framework that conceptualizes visual perceptual skill as a hierarchy in adults with ABI [32]. Cilo et al., Ripley et al., and Cohen and Rein have all described the importance of integrating the "vision specialist" (optometrist and/or the ophthalmologist) into the interdisciplinary rehabilitation treatment team [33-36].

Table.

Visual impairments and visual functional deficits.

\begin{tabular}{|c|c|c|}
\hline Visual Impairment & Prevalence (\%) & Visual Functional Deficits $[1,8,16-19,22]$ \\
\hline Accommodative Deficits & $31-41$ & Difficulty with reading and writing tasks, diplopia, blurred vision \\
\hline Vergence Deficits & $40-56$ & Difficulty with reading and writing tasks, diplopia, blurred vision \\
\hline Pursuit/Saccade Deficits & 29 & Difficulty with reading and writing tasks, diplopia, blurred vision \\
\hline Diplopia & 19 & Blurred vision, balance deficits, nausea, reading deficits, visual motor deficits \\
\hline Fixation Deficits & $9-13$ & Difficulty with reading and writing tasks, diplopia, blurred vision \\
\hline Visual Field Deficits & $\begin{array}{l}46 \text { (39 TBI, } \\
67 \text { CVA) }\end{array}$ & Difficulty with reading and writing tasks, ADL and IADL deficits, mobility deficit \\
\hline Visual Acuity Deficits & 21 & $\begin{array}{l}\text { Difficulty with reading and writing tasks, difficulty with mobility and navigation, } \\
\text { ADL and IADL deficits }\end{array}$ \\
\hline
\end{tabular}


Suter and Harvey and Ashley describe a model for guiding vision rehabilitation of the complex visual system, including its integration with other sensory and output systems [37-38]. A four-tiered conceptual model of optometric care in TBI patients described by Ciuffueda and Ludlam included the basic optometric examination and analysis of ocular motor problems, nonocular motor problems, and non-vision-based problems [39]. Furthermore, others have published reports on the importance of screening for vision problems in select populations. For example, Radmonski et al. discusses the importance of routine vision screening as it relates to treatment planning and the referral to vision specialists [40]. Goodrich et al. developed a screening protocol that includes historical questions and examination techniques to provide a set of standardized clinical guidelines [41]; this tool can be leveraged as either a screen for or as an adjunct to a full eye examination in order to provide optimal and uniform vision care for the patient with mild TBI. Despite these cogent practice guidelines, concepts, screens, and models that shed light on various domains within the intersection between neurorehabilitation and the visual system, there is still not a universally accepted, interprofessional model for comprehensive vision assessment and management in a rehabilitation setting.

The American Congress of Rehabilitation Medicine's (ACRM's) Vision Task Force members have identified this as a problem and as a causal influence for the lack of communication and understanding between rehabilitation clinicians. This lack of translation and communication may have contributed to an absence of interprofessional assessment and treatment plans to identify and address visual impairment. In this article, a novel, comprehensive, and interprofessional conceptual model for vision rehabilitation is described. Key terms are defined and strategies are delineated regarding application and integration in clinical practice across all disciplines.

\section{PROPOSED CONCEPTUAL MODEL FOR VISION REHABILITATION}

\section{Background on Development}

The ACRM Stroke Interdisciplinary Special Interest Group (ISIG) identified this emerging practice area as underrepresented and deserving of increased and focused attention. An interprofessional vision task force comprised of ophthalmologists, optometrists, physiatrists, occupa- tional therapists, and neuropsychologists was formed to examine the gaps in vision rehabilitation and propose a conceptual model to provide a framework for approaching vision rehabilitation in clinical practice. During the early meetings, the task force created the model element by element, starting with first contact in a healthcare setting and ending with targeted interventions. The model relates visual system assessment to impairments, activity limitations, and participation restrictions in the broader function and quality of life domains (Figure 1).

The model's foundation was started with reference to the WHO's International Classification of Functioning, Disability, and Health (ICF) framework, emphasizing the interconnection between diagnostic assessment and therapeutic intervention in interprofessional vision care [2]. ICF terminology highlights major factors that support function, including impairment, activity, participation, and contextual factors [2]. These dimensions in the classification system require practitioners, regardless of their discipline, to utilize this vocabulary and create a universal thought construct for assessments and intervention, allowing for more thorough clinical approaches that lend themselves to comparisons. The field of medical rehabilitation has been and is trained to work within this framework, focusing on body structure, function, activity, participation, environmental factors, and personal factors.

\section{Definitions for Conceptual Model}

To organize the conceptual model for vision rehabilitation, it was imperative to determine a standard language and classification framework. "Visual function" and "functional vision" are the key terms that differentiate the two core domains within the conceptual model. Visual function describes how the eye, as an organ, and lower-order cerebral mechanisms function [42]; the term visual impairments is used to describe deficits in this context. Functional vision describes how the person functions and indicates deficits in higher-order cerebral mechanisms [43-44], and when describing deficits in this context, the term visual dysfunction is utilized. These distinct terms stress that visual function and functional vision represent aspects that require different, albeit interrelated, approaches to the comprehensive examination of vision. Additionally, these furtherdelineated domains not only permit identification of impairments and dysfunction but also communication between care providers, establishing the link between organ and function that is essential to rehabilitation and recovery. 


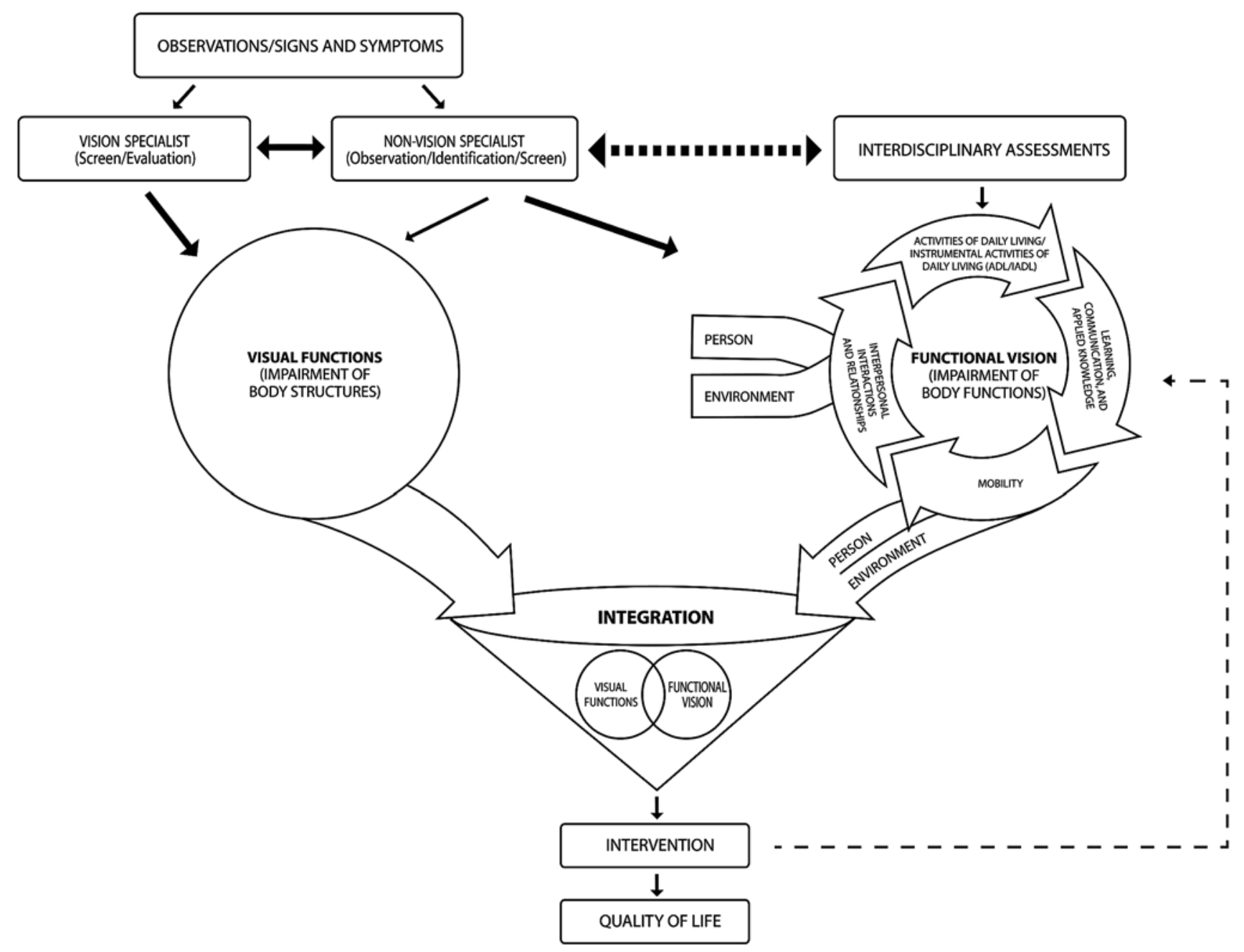

Figure 1.

Conceptual model for vision rehabilitation.

The diagnosticians in this framework are categorized as "vision specialists" and "non-vision specialists" (clinicians). The vision specialists are the ophthalmologists, optometrists, or other professionals who specialize in vision rehabilitation and who historically assess the visual system and how it functions, primarily at the lower-order cerebral mechanism level, although at times they may also assess the higher-order level. Often vision specialists are initially consultants and are then integrated into the traditional interprofessional rehabilitation team. The non-vision specialists (clinicians) include members of the interprofessional rehabilitation team, encompassing physicians, nurses, occupational therapists, physical therapists, speech-language pathologists, neuropsychologists/psychologists, and thera- peutic recreation specialists. All members of the rehabilitation team address vision directly or indirectly in a broader context and assist in the detection of visual dysfunction at the higher-order cerebral level and visual impairment at the lower-order level; the primary focus for the broader context within rehabilitation is always function and quality of life.

Traditionally, an ophthalmologist or optometrist provides vision care as the focus of their practice. Ophthalmologists are medical physicians who provide comprehensive medical, surgical, and optical care at the organ level [32]. Optometrists focus on the eyes and related visual structures, as well as the lower-order and, more variably, the higherorder visual systems, including visual information processing in humans at the organ and person level [31]. In terms 
of vision rehabilitation, ophthalmologists and optometrists, in conjunction with other vision specialists (e.g., OD, VRT, etc.) and non-vision specialists (e.g., OT, PT, SLP, etc.), often work together to determine treatment programs that are prescribed and monitored to support, integrate, and enhance visual input and processing skills and address ADL/IADL. Most commonly, unless an ocular emergency presents, ophthalmologists and optometrists are not part of the acute medical team and, consequently, are often unable to assess a patient's visual status immediately following or even shortly after a neurological event.

By contrast, the non-vision specialists (clinicians), including the interprofessional rehabilitation team, may have contact with an individual soon after an acute neurological event. These clinicians are keen observers on the frontline in care models, spending significant periods of time with the patients in a hands-on, functional capacity. This is the optimal position in which to observe higher-order cerebral mechanisms of vision. However, current practice predominantly supports their involvement in assessing meta-level functional implications, often focusing on the totality of impairments and how to remediate these deficits with broad strategies to compensate, substitute, and remediate. While this is undoubtedly essential, it leaves to be determined whether highlighting and focusing on the underlying visual impairments and dysfunction with more specificity could further assist in optimizing functional improvement. This is where the vision specialists with an interest and education in vision rehabilitation can bridge the gap. The proposed framework communicates an integrated approach in which frontline non-vision specialists (clinicians) communicate the broader functional vision perspective and collaborate with the vision specialists as they narrow in on the vision impairment, connecting the associated dysfunction or functional vision to the visual function, a construct that is paramount to the comprehensive assessment model.

Figure 1 illustrates the important interaction between the vision specialist and non-vision specialist (clinician), enabling dialog to improve the sensitivity and specificity of visual screening. For example, following initial screening and detection, the vision specialist may initiate care by diagnosing visual function (organ) impairment on the lower-order cerebral level or body structure level, i.e., retina to optic nerve to visual cortices (circle on the left side of the schematic). However, knowing how the eyes function does not fully inform the clinician about how the person functions on the body level (the circle on the right side of the schematic). For this reason, we stress the importance of the non-vision specialist (clinician) roles to further screen for dysfunction. The model standardizes the nomenclature and organizes a process to systematically integrate assessment of the organ-level impairment (visual function) and person-level dysfunction (functional vision).

The combination of specialists' care is highlighted in the figure as the overlapping circular areas and represents an interprofessional approach to patient-centered care (the funnel in the central portion of the schematic). The comprehensive assessments will assist clinicians in determining how vision affects the broad categories of mobility, learning, communication, applied knowledge, ADL, IADL, interpersonal interactions, leisure activities, work, and relationships (detailed in the circular cycle on the right side of the schematic). For example, a patient who has had a stroke with a resultant left homonymous hemianopsia will interact and communicate with the world differently, and accommodations will undoubtedly be necessitated. Whether accommodations include strategies to navigate safely in crowded environments or an instruction set focusing on IADL, integration of vision rehabilitation is a mandatory overlay for comprehensive stroke rehabilitation. In addition, the focus areas identified by the functional assessment will inform interventions that facilitate functional vision (Figure 2).

The key is integration. The natural relationship between the organ-level assessment for visual function and the person-level assessment for functional vision is consistent with the ICF framework as previously stated. Following this union, the non-vision specialist (clinician) and the vision specialist can better provide therapeutic interventions that are tailored to the individual's needs and designed to remediate the vision function impairment and the functional vision dysfunction, targeting health, wellbeing, and quality of life.

\section{Scientific Rationale, Evidence, and Translation}

Typically, a professional's screening method is influenced by a multitude of factors that may include workplace behaviors, responsibilities, collaborations/partnerships, research projects, mentorship, and/or expected standards at a particular institution. Despite these influences, it is very important to make sure that best practice guidelines are followed and that the guidelines are evidence based. This goal becomes exceedingly difficult if a practice framework or conceptual model does not exist to reference or provide guidance to the interprofessional team. 


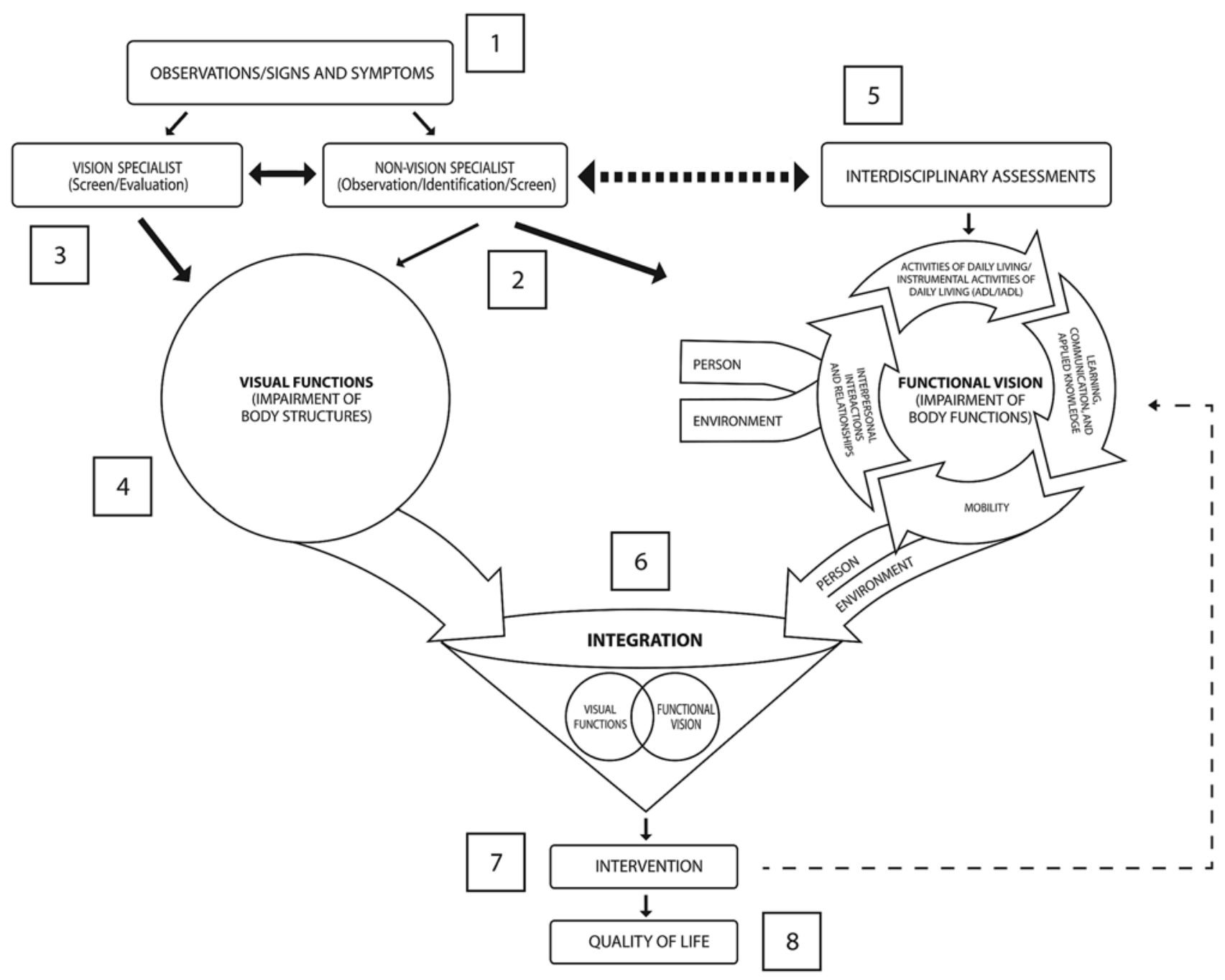

Figure 2.

Conceptual model for vision rehabilitation example.

It is well known that disease severity is manifested clinically by its effect on general function, a key metric used to determine intervention and subsequent follow-up [45-48]. In fact, only by testing functional vision in different modalities, in combination with visual function and under different conditions, can the treatment providers gain an understanding of the comprehensive deficits and their associated severities [48]. The vision conceptual model underscores the importance of an interprofessional assessment, given the complex nature of vision and its functional correlates. Moreover, visual function and functional vision are far from unidimensional con- structs and need a multifaceted assessment and treatment approach with clinicians of disparate backgrounds.

Interprofessional collaboration during vision assessment and its related functional correlates is of great importance, and improved dialog between professionals may lead to better patient outcomes. When professionals work together, optimized and cost-effective outcomes may be achieved with the potential for less redundancy in diagnostic testing and expeditious therapeutic planning. This collegiality allows for clinicians to learn from each other, to engage in the clinical audit of outcomes together, and to generate innovative solutions, ensuring progressive practice and service [49]. A pivotal step in safeguarding the success 
of this conceptual model and the interprofessional dialog, as previously described, is a lexicon and framework that scaffolds onto vision function and functional vision. Ultimately, this model may allow the interprofessional team to anticipate which interventions will yield the best results and where expected gains may have synergistic effects on functional vision or performance level. Reporting these positive outcomes or negative results to the broader team and contextualizing them in the framework will ensure expeditious pivots in intervention and customized approaches that may yield continually improving outcomes.

As vision function and functional vision exist on a continuous spectrum, basic visual impairments (e.g., acuity, oculomotor skills) result in poor performance on more complex and advanced visuoperceptual tasks [50]. As noted previously, Warren [32] established a hierarchical model of visual-spatial abilities in which the most basic skills form the foundation for each successive level. At the ground level, visuoperceptual skills begin with oculomotor control, visual fields, and visual acuity, with an ascending hierarchy involving attention, scanning, pattern recognition, visual memory, and visual cognition (managing more complex and integrated visual processing skills). In summary, many aspects of visual perception may be impaired by ocular disorders or neurological dysfunction; infrequently, the visuoperceptual disorder will be confined to a single or small set of impairments and dysfunctions. Thus, the interplay of visual function and functional vision is extensive and pervasive. This conceptual model for vision rehabilitation is a catalyst for addressing the comprehensive, interprofessional approach to vision assessment and treatment.

The evidence abounds for the concept of structured visual examinations for patients with ABI [17,36,48-49]. Furthermore, if we assume that the integration of "vision specialists" into our rehabilitation team is successful, ample evidence suggests that visual deficits can be remediated through vision rehabilitation [50-55]. Padula et al. have developed comprehensive courses to address visual impairment and subsequent dysfunction and even proposed changes in legislation to better address these needs [56-58]. Kerkhoff et al. [59-62] have developed a comprehensive model of visual ability concentrated in four main activity types: mobility, binocular vision, reading, and visual memory, highlighting the implications for rehabilitation and this construct as a framework for therapeutic approaches [20]. As a tangible example, it is well established that sports-specific or drill-specific training can affect oculomotor behavior, a correlate for vision rehabili- tation, revealing that therapeutic exercise can modulate visuomotor skills [63-67].

As described briefly in the "Introduction," previous research supports the need for a comprehensive approach to vision care following brain injury [33,35,37]. Vision specialists are an important part of a broader interprofessional team. The pivotal role vision plays in performance and function has been described [68-70] and must be a core feature that is integrated into an intellectual framework. Moreover, our maturing population, with increasing rates of sight-threatening, age-related conditions, could compound issues with visual impairment and dysfunction secondary to brain injury [71], which can affect the patient more severely on the person level or functional vision level. It has already been shown that these expanding, age-related visually compromising conditions interface with rehabilitation [72-76], and these novel concepts [58,75,77-80], as delineated previously, must account for and integrate these disorders into the framework to expand the knowledge base accordingly.

\section{Recommendations, Future Directions, and Clinical Inferences}

There has been limited documentation emphasizing the value of interprofessional assessment and treatment related to visual function and functional vision. The use of a conceptual model for understanding these constructs within an interprofessional approach to vision rehabilitation can guide both assessment and, subsequently, treatment in a more thorough and cohesive manner, leading to improved patient care and outcomes. Regardless of discipline, professionals can utilize this model as a framework to improve practice standards because (1) it is a guide to address how visual function and functional vision can be systematically approached in an integrated fashion, and (2) it can assist the individual team members in selecting appropriate referrals, conceptualizing assessment, initiating intervention, and improving communication with the interprofessional team.

Future directions for vision rehabilitation include presenting in educational forums at the regional and national levels, collaborating with accreditation agencies, and initiating dialog with payers to include functional vision as a necessary element to be addressed and reimbursed for in rehabilitation. 


\section{CONCLUSIONS}

In conclusion, incorporating vision specialists into the care team and understanding the integration of both functional vision and visual function into a core knowledge base, as communicated by this conceptual model, provides the foundation for optimal assessment and therapeutic remediation. This model could ultimately affect quality of life and patient safety with appropriate assessment and utilization of an expanded, interprofessional approach to assessing the visual function-functional vision spectrum. To this end, clinicians will have the opportunity to ensure that effective compensatory, substitutive, and restorative interventions are efficiently deployed [45].

\section{ACKNOWLEDGMENTS}

\author{
Author Contributions: \\ Study concept and design: P. S. Roberts (co-first author), J. Rizzo (co-first \\ author), K. Hreha, J. Wertheimer, J. Kaldenberg, D. Hironaka. \\ Analysis and interpretation: P. S. Roberts, J. Rizzo, K. Hreha, \\ J. Wertheimer, J. Kaldenberg, D. Hironaka. \\ Drafting manuscript: P. S. Roberts, J. Rizzo, K. Hreha, J. Wertheimer, \\ J. Kaldenberg, D. Hironaka. \\ Critical revision of manuscript for important intellectual content: \\ P. S. Roberts, J. Rizzo, K. Hreha, J. Wertheimer, J. Kaldenberg, \\ D. Hironaka, R. Riggs, A. Colenbrander. \\ Study collaboration and supervision: P. S. Roberts, J. Rizzo. \\ Study supervision: R. Riggs, A. Colenbrander.
}

Financial Disclosures: The authors have declared that no competing interests exist.

Funding/Support: This material was unfunded at the time of manuscript preparation.

Additional Contributions: This manuscript is a product of the dedicated members on the Vision Task Force, which is part of ACRM's Stroke ISIG. We would also like to recognize Kelly Hironaka for her assistance in the development of the conceptual model's graphics and Mary Warren for her expertise and invaluable input in the initial phases of the model development. Parts of this work have been previously presented: Roberts PS, Rizzo JR, Hreha K, Wertheimer J, Kaldenberg J, Hironaka D, Riggs R, Colenbrander A. A conceptual model for vision rehabilitation: Recommendations from the American Congress of Rehabilitation Medicine Vision Taskforce and Roberts PS, Rizzo JR, Hreha K, Riggs R. Early integration of vision into stroke rehabilitation [Instructional course]. ACRM 90th Annual Conference: Progress in Rehabilitation Research; 2013 Nov 12-16; Orlando, Florida.

\section{REFERENCES}

1. Ciuffreda KJ, Kapoor N, Rutner D, Suchoff IB, Han ME, Craig S. Occurrence of oculomotor dysfunctions in acquired brain injury: A retrospective analysis. Optometry. 2007;78(4):155-61. [PMID:17400136]

http://dx.doi.org/10.1016/j.optm.2006.11.011

2. World Health Organization International Classification of Functioning, Disability, and Health (ICF). Geneva (Switzerland): World Health Organization; 2001.

3. Klein BE, Klein R, Lee KE, Cruickshanks KJ. Performance-based and self-assessed measures of visual function as related to history of falls, hip fractures, and measured gait time. The Beaver Dam Eye Study. Ophthalmology. 1998;105(1):160-64. [PMID:9442793] http://dx.doi.org/10.1016/S0161-6420(98)91911-X

4. McCarty CA, Fu CL, Taylor HR. Predictors of falls in the Melbourne visual impairment project. Aust N Z J Public Health. 2002;26(2):116-19. [PMID:12054328] http://dx.doi.org/10.1111/j.1467-842X.2002.tb00902.x

5. Ivers RQ, Cumming RG, Mitchell P, Attebo K. Visual impairment and falls in older adults: The Blue Mountains Eye Study. J Am Geriatr Soc. 1998;46(1):58-64. [PMID:9434666] http://dx.doi.org/10.1111/j.1532-5415.1998.tb01014.x

6. Silverstone B, Lang MA, Rosenthal B, Faye EE. The Lighthouse Handbook on vision impairment and vision rehabilitation: 2 vol. Oxford (UK): Oxford University Press; 2000.

7. Horowitz A. Depression and vision and hearing impairments in later life. Generations. 2003;27(1):32-38.

8. West SK, Rubin GS, Broman AT, Muñoz B, BandeenRoche K, Turano K. How does visual impairment affect performance on tasks of everyday life? The SEE Project. Salisbury Eye Evaluation. Arch Ophthalmol. 2002;120(6): 774-80. [PMID:12049583] http://dx.doi.org/10.1001/archopht.120.6.774

9. Feinberg JL, Rogers PA, Sokol-Mckay D. Age-related eye disease and medication safety. Annals of Long-Term Care. 2009;17(6):17-22.

10. Wang JJ, Mitchell P, Simpson JM, Cumming RG, Smith W. Visual impairment, age-related cataract, and mortality. Arch Ophthalmol. 2001;119(8):1186-90. [PMID:11483087] http://dx.doi.org/10.1001/archopht.119.8.1186

11. Wang JJ, Mitchell P, Smith W, Cumming RG, Attebo K. Impact of visual impairment on use of community support services by elderly persons: The Blue Mountains Eye Study. Invest Ophthalmol Vis Sci. 1999;40(1):12-19. [PMID:9888421]

12. Zheng DD, Christ SL, Lam BL, Arheart KL, Galor A, Lee DJ. Increased mortality risk among the visually impaired: The roles of mental well-being and preventive care practices. Invest Ophthalmol Vis Sci. 2012;53(6):2685-92.

[PMID:22427599]

http://dx.doi.org/10.1167/iovs.11-8794 
13. Van Essen DC, Drury HA. Structural and functional analyses of human cerebral cortex using a surface-based atlas. J Neurosci. 1997;17(18):7079-7102. [PMID:9278543]

14. Jacobson S, Marcus EM. Neuroanatomy for the neuroscientist. 2nd ed. New York (NY): Springer; 2011. p. 255-73.

15. Rowe FJ, Wright D, Brand D, Jackson C, Harrison S, Maan T, Scott C, Vogwell L, Peel S, Akerman N, Dodridge C, Howard C, Shipman T, Sperring U, MacDiarmid S, Freeman C. A prospective profile of visual field loss following stroke: Prevalence, type, rehabilitation, and outcome. Biomed Res Int. 2013;2013:719096.

16. Suchoff IB, Kapoor N, Ciuffreda KJ, Rutner D, Han E, Craig $\mathrm{S}$. The frequency of occurrence, types, and characteristics of visual field defects in acquired brain injury: A retrospective analysis. Optometry. 2008;79(5):259-65. [PMID:18436166] http://dx.doi.org/10.1016/j.optm.2007.10.012

17. Cockerham GC, Goodrich GL, Weichel ED, Orcutt JC, Rizzo JF, Bower KS, Schuchard RA. Eye and visual function in traumatic brain injury. J Rehabil Res Dev. 2009; 46(6):811-18. [PMID:20104404] http://dx.doi.org/10.1682/JRRD.2008.08.0109

18. Brahm KD, Wilgenburg HM, Kirby J, Ingalla S, Chang CY, Goodrich GL. Visual impairment and dysfunction in combat-injured servicemembers with traumatic brain injury. Optom Vis Sci. 2009;86(7):817-25. [PMID:19521270] http://dx.doi.org/10.1097/OPX.0b013e3181adff2d

19. Kerkhoff G. Neurovisual rehabilitation: Recent developments and future directions. J Neurol Neurosurg Psychiatry. 2000; 68(6):691-706. [PMID:10811691] http://dx.doi.org/10.1136/jnnp.68.6.691

20. Wolter M, Preda S. Visual deficits following stroke: Maximizing participation in rehabilitation. Top Stroke Rehabil. 2006;13(3):12-21. [PMID:16987788] http://dx.doi.org/10.1310/3JRY-B168-5N49-XQWA

21. Horowitz A. The prevalence and consequences of vision impairment in later life. Top Geriatr Rehabil. 2004;20(3): 185-95. http://dx.doi.org/10.1097/00013614-200407000-00006

22. Papageorgiou E, Hardiess G, Schaeffel F, Wiethoelter H, Karnath $\mathrm{HO}$, Mallot H, Schoenfisch B, Schiefer U. Assessment of vision-related quality of life in patients with homonymous visual field defects. Graefes Arch Clin Exp Ophthalmol. 2007;245(12):1749-58. [PMID:17653566] http://dx.doi.org/10.1007/s00417-007-0644-z

23. Chin HS, Park SH, Park IK, Kwon JW, Lee SJ; Steering Committee of Korean Guides for Impairment Rating in Korean Academy of Medical Sciences. Guideline development for the evaluation of visual impairment in Korea. J Korean Med Sci. 2009;24(2 Suppl 2):S252-57. [PMID:19503681] http://dx.doi.org/10.3346/jkms.2009.24.S2.S252
24. Colenbrander A. Aspects of vision loss-visual functions and functional vision. Vis Impair Res. 2003;5(3):115-36. http://dx.doi.org/10.1080/1388235039048919

25. Colenbrander A. Visual functions and functional vision. Int Congr Ser. 2005;1282:482-86. http://dx.doi.org/10.1016/j.ics.2005.05.002

26. Solomon D, Goldstein J. Chapter 15: Visual, oculomotor and vestibular deficits. Stein J, Harvey RL, Macko RF, Winstein CJ, Zorowitz RD, editors. Stroke recovery and rehabilitation. New York (NY): Demos Medical Publishing; 2009. p. 227-44.

27. American Academy of Ophthalmology Vision Rehabilitation Committee. Preferred Practice Pattern ${ }^{\circledR}$ Guidelines: Vision rehabilitation for adults [Internet]. San Francisco (CA): American Academy of Ophthalmology; 2013 [cited 2014 May 12]. Available from: www.aao.org/ppp

28. Suchoff IB, Gianutsos R. Rehabilitative optometric interventions for the acquired brain injured adult. In: Grabois M, Garrison SJ, Hart KA, Lehmkuhl D, editors. Physical medicine and rehabilitation: The complete approach. New York (NY): Blackwell Scientific; 2000.

29. Kaldenberg J, Smallfield S. Occupational therapy practice guidelines for older adults with low vision. Bethesda (MD): American Occupational Therapy Association, Inc; 2013.

30. Neuro-Optometric Rehabilitation Association (NORA) [Internet]. Valencia (CA): NORA; [cited 2015 Jan 25]. Available from: https://nora.cc/

31. American Optometric Association: Vision Rehabilitation Section. Brain injury electronic resource manual-Volume 1A: Traumatic brain injury visual dysfunction diagnosis [Internet]. 2013 [cited 2015 Dec 3]. Available from: http://aoa.uberflip.com/i/225867-brain-injury-electronicresource-manual

32. Warren M. A hierarchical model for evaluation and treatment of visual perceptual dysfunction in adult acquired brain injury, Part 1. Am J Occup Ther. 1993;47(1):42-54. [PMID:8418676] http://dx.doi.org/10.5014/ajot.47.1.42

33. Cilo M, Politzer T, Ripley DL, Weintraub A. Vision examination of TBI patients in an acute rehabilitation hospital. NeuroRehabilitation. 2010;27(3):237-42. [PMID:21098992]

34. Ripley DL, Politzer T, Berryman A, Rasavage K, Weintraub A. The vision clinic: An interdisciplinary method for assessment and treatment of visual problems after traumatic brain injury. NeuroRehabilitation. 2010;27(3):231-35. [PMID:21098991]

35. Cohen AH. Optometry: The invisible member of the rehabilitation team. J Am Optom Assoc. 1992;63(8):529. [PMID:1512400]

36. Cohen AH, Rein LD. The effect of head trauma on the visual system: The doctor of optometry as a member of the rehabilitation team. J Am Optom Assoc. 1992;63(8):530-36.

[PMID:1512401] 
37. Suter PS, Harvey LH. Vision rehabilitation: Multidisciplinary care of the patient following brain injury. Burlington (MA): Taylor \& Francis; 2011.

38. Ashley MJ. Traumatic brain injury: Rehabilitation, treatment, and case management. 3rd ed. Burlington (MA): Taylor \& Francis; 2010.

39. Ciuffreda KJ, Ludlam DP. Conceptual model of optometric vision care in mild traumatic brain injury. J Behav Optom. 2011;22(1):10-12.

40. Radomski MV, Finkelstein M, Llanos I, Scheiman M, Wagener SG. Composition of a vision screen for servicemembers with traumatic brain injury: Consensus using a modified nominal group technique. Am J Occup Ther. 2014;68(4):422-29. [PMID:25005505] http://dx.doi.org/10.5014/ajot.2014.011445

41. Goodrich GL, Martinsen GL, Flyg HM, Kirby J, Asch SM, Brahm KD, Brand JM, Cajamarca D, Cantrell JL, Chong T, Dziadul JA, Hetrick BJ, Huang MA, Ihrig C, Ingalla SP, Meltzer BR, Rakoczy CM, Rone A, Schwartz E, Shea JE; U.S. Department of Veterans Affairs. Development of a mild traumatic brain injury-specific vision screening protocol: A Delphi study. J Rehabil Res Dev. 2013;50(6):757-68. [PMID:24203539]

42. Colenbrander A. The functional classification of brain damage-related vision loss. J Vis Impair Blind. 2009;103(2): 118-23.

43. Lezak M, Howieson D, Loring D. Neuropsychological assessment. 4th ed. Oxford (UK): Oxford University Press; 2004.

44. Shaw J. The assessment and rehabilitation of visuo-spatial disorders. In: Johnston B, Stonnington H, editors. Rehabilitation of neuropsychology disorders. New York (NY): Psychology Press; 2001. p. 125-160.

45. Balcer LJ, Miller DH, Reingold SC, Cohen JA. Vision and vision-related outcome measures in multiple sclerosis. Brain. 2015;138(Pt 1):11-27. [PMID:25433914] http://dx.doi.org/10.1093/brain/awu335

46. Fisher JB, Jacobs DA, Markowitz CE, Galetta SL, Volpe NJ, Nano-Schiavi ML, Baier ML, Frohman EM, Winslow H, Frohman TC, Calabresi PA, Maguire MG, Cutter GR, Balcer LJ. Relation of visual function to retinal nerve fiber layer thickness in multiple sclerosis. Ophthalmology. 2006; 113(2):324-32. [PMID:16406539]

http://dx.doi.org/10.1016/j.ophtha.2005.10.040

47. Sakai RE, Feller DJ, Galetta KM, Galetta SL, Balcer LJ. Vision in multiple sclerosis: The story, structure-function correlations, and models for neuroprotection. J Neuroophthalmol. 2011;31(4):362-73. [PMID:22089500] http://dx.doi.org/10.1097/WNO.0b013e318238937f

48. Gianutsos R, Ramsey G, Perlin RR. Rehabilitative optometric services for survivors of acquired brain injury. Arch Phys Med Rehabil. 1988;69(8):573-78. [PMID:3408326]
49. Padula WV, Ikeda E, Fong D, Vicci V. The need for optometric rehabilitation for our veterans who have incurred a traumatic brain injury: Senate Bill 1999/House Bill 3558. Optometry. 2008;79(4):170-71. [PMID:18358995] http://dx.doi.org/10.1016/j.optm.2008.02.003

50. Thiagarajan P, Ciuffreda KJ, Capo-Aponte JE, Ludlam DP, Kapoor N. Oculomotor neurorehabilitation for reading in mild traumatic brain injury (mTBI): An integrative approach. NeuroRehabilitation. 2014;34(1):129-46. [PMID:24284470]

51. Ciuffreda KJ, Han Y, Kapoor N, Ficarra AP. Oculomotor rehabilitation for reading in acquired brain injury. NeuroRehabilitation. 2006;21(1):9-21. [PMID:16720933]

52. Ciuffreda KJ, Rutner D, Kapoor N, Suchoff IB, Craig S, Han ME. Vision therapy for oculomotor dysfunctions in acquired brain injury: A retrospective analysis. Optometry. 2008;79(1):18-22. [PMID:18156092] http://dx.doi.org/10.1016/j.optm.2007.10.004

53. Gottlieb DD, Fuhr A, Hatch WV, Wright KD. Neurooptoetric facilitation of vision recovery after acquired brain injury. NeuroRehabilitation. 1998;11(3):175-99.

[PMID:24525922]

http://dx.doi.org/10.1016/S1053-8135(98)00021-3

54. Kapoor N, Ciuffreda KJ, Han Y. Oculomotor rehabilitation in acquired brain injury: A case series. Arch Phys Med Rehabil. 2004;85(10):1667-78. [PMID:15468029] http://dx.doi.org/10.1016/j.apmr.2003.12.044

55. Yadav NK, Thiagarajan P, Ciuffreda KJ. Effect of oculomotor vision rehabilitation on the visual-evoked potential and visual attention in mild traumatic brain injury. Brain Inj. 2014;28(7):922-29. [PMID:24564831] http://dx.doi.org/10.3109/02699052.2014.887227

56. Padula WV, Argyris S. Post trauma vision syndrome and visual midline shift syndrome. NeuroRehabilitation. 1996; 6(3):165-71. [PMID:24525768] http://dx.doi.org/10.1016/1053-8135(96)00162-X

57. Padula WV, Argyris S, Ray J. Visual evoked potentials (VEP) evaluating treatment for post-trauma vision syndrome (PTVS) in patients with traumatic brain injuries (TBI). Brain Inj. 1994;8(2):125-33. [PMID:8193632] http://dx.doi.org/10.3109/02699059409150964

58. Padula WV. Low vision related to function and rehabilitation. Yan Ke Xue Bao. 1986;2(2):103-8. [PMID:3333636]

59. Kerkhoff G, Marquardt C. [Visually based reading disorders after brain damage. Standardised assessment and treatment with READ]. Nervenarzt. 2009;80(12):1424-39. German. [PMID:19484214] http://dx.doi.org/10.1007/s00115-009-2723-3

60. Kerkhoff G, Münssinger U, Meier EK. Neurovisual rehabilitation in cerebral blindness. Arch Neurol. 1994;51(5): 474-81. [PMID:8179497] http://dx.doi.org/10.1001/archneur.1994.00540170050016 
61. Kerkhoff G, Münßinger U, Haaf E, Eberle-Strauss G, Stögerer E. Rehabilitation of homonymous scotomata in patients with postgeniculate damage of the visual system: Saccadic compensation training. Restor Neurol Neurosci. 1992;4(4):245-54. [PMID:21551879]

62. Kerkhoff G, Stögerer E. [Treatment of fusional disorders in patients with brain damage]. Klin Monatsbl Augenheilkd. 1994;205(2):70-75. German. [PMID:7967409] http://dx.doi.org/10.1055/s-2008-1045495

63. Zupan M, Wile A. Eyes on the prize. Train Condit. 2011; 21(2):1-3.

64. Shapiro KL, Raymond JE. Training of efficient oculomotor strategies enhances skill acquisition. Acta Psychol (Amst). 1989;71(1-3):217-42. [PMID:2816474] http://dx.doi.org/10.1016/0001-6918(89)90010-3

65. Savelsbergh GJ, Williams AM, Van der Kamp J, Ward P. Visual search, anticipation and expertise in soccer goalkeepers. J Sports Sci. 2002;20(3):279-87. [PMID:11999482] http://dx.doi.org/10.1080/026404102317284826

66. Savelsbergh GJ, Van der Kamp J, Williams AM, Ward P. Anticipation and visual search behaviour in expert soccer goalkeepers. Ergonomics. 2005;48(11-14):1686-97. [PMID:16338733] http://dx.doi.org/10.1080/00140130500101346

67. Piras A, Lobietti R, Squatrito S. A study of saccadic eye movement dynamics in volleyball: Comparison between athletes and non-athletes. J Sports Med Phys Fitness. 2010; 50(1):99-108. [PMID:20308980]

68. Colenbrander A. Dimensions of visual performance. Trans Sect Ophthalmol Am Acad Ophthalmol Otolaryngol. 1977; 83(2):332-37. [PMID:141761]

69. Colenbrander A. Letter: Classification of visual performance. Am J Optom Physiol Opt. 1976;53(5):274. [PMID:937506] http://dx.doi.org/10.1097/00006324-197605000-00010

70. Colenbrander A. Assessment of functional vision and its rehabilitation. Acta Ophthalmol. 2010;88(2):163-73. [PMID:20039847] http://dx.doi.org/10.1111/j.1755-3768.2009.01670.x

71. Seidman K, Strand C. Vision rehabilitation. A missing link in client care. Care Manag J. 2000;2(3):169-77. [PMID:11398573]

72. Colenbrander A, Fletcher DC. Low vision rehabilitation: Visual acuity measurement in the low vision range. J Ophthalmic Nurs Technol. 1992;11(2):62-69. [PMID:1564739]

73. Colenbrander A, Goodwin L, Fletcher DC. Vision rehabilitation and AMD. Int Ophthalmol Clin. 2007;47(1):139-48. [PMID:17237678] http://dx.doi.org/10.1097/IIO.0b013e31802bd939

74. Archambault P, Colenbrander A. Visual results with lowvision aids in age-related macular degeneration. Am J Ophthalmol. 1989;107(5):564-66. [PMID:2712148] http://dx.doi.org/10.1016/0002-9394(89)90517-5
75. Brown B, Brabyn L, Welch L, Haegerstrom-Portnoy G, Colenbrander A. Contribution of vision variables to mobility in age-related maculopathy patients. Am J Optom Physiol Opt. 1986;63(9):733-39. [PMID:3777123] http://dx.doi.org/10.1097/00006324-198609000-00006

76. Brown B, Zadnik K, Bailey IL, Colenbrander A. Effect of luminance, contrast, and eccentricity on visual acuity in senile macular degeneration. Am J Optom Physiol Opt. 1984;61(4):265-70. [PMID:6731572] http://dx.doi.org/10.1097/00006324-198404000-00006

77. Pijnacker J, Verstraten P, van Damme W, Vandermeulen J, Steenbergen B. Rehabilitation of reading in older individuals with macular degeneration: A review of effective training programs. Neuropsychol Dev Cogn B Aging Neuropsychol Cogn. 2011;18(6):708-32. [PMID:21992418] http://dx.doi.org/10.1080/13825585.2011.613451

78. Seiple W, Szlyk JP, McMahon T, Pulido J, Fishman GA. Eye-movement training for reading in patients with agerelated macular degeneration. Invest Ophthalmol Vis Sci. 2005;46(8):2886-96. [PMID:16043863] http://dx.doi.org/10.1167/iovs.04-1296

79. Wu DZ, Wu L, Chang FX, Jin C, Padula W. Visual rehabilitation in low vision patients with aging macular degeneration. J Am Optom Assoc. 1995;66(1):39-41.

[PMID:7884140]

80. Déruaz A, Goldschmidt M, Whatham AR, Mermoud C, Lorincz EN, Schnider A, Safran AB. A technique to train new oculomotor behavior in patients with central macular scotomas during reading related tasks using scanning laser ophthalmoscopy: Immediate functional benefits and gains retention. BMC Ophthalmol. 2006;6:35. [PMID:17123448] http://dx.doi.org/10.1186/1471-2415-6-35

Submitted for publication June 17, 2015. Accepted in revised form December 15, 2015.

This article and any supplementary material should be cited as follows:

Roberts PS, Rizzo J, Hreha K, Wertheimer J, Kaldenberg J, Hironaka D, Riggs R, Colenbrander A. A conceptual model for vision rehabilitation. J Rehabil Res Dev. 2016; 53(6):693-704.

http://dx.doi.org/10.1682/JRRD.2015.06.0113

ORCID: Pamela S. Roberts, PhD, OTR/L, SCFES, FAOTA, CPHQ, FNAP: 0000-0002-1675-3782

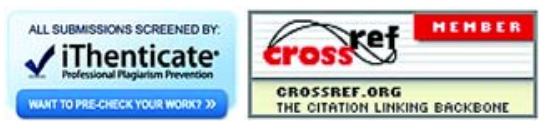


